\title{
Pengaruh Penggunaan Handout Antagonisme dalam Pembelajaran Biologi terhadap Hasil Belajar Kognitif
}

\author{
Arif Rahman ${ }^{1}$, Utami Sri Hastuti ${ }^{1}$, Fatchur Rohman ${ }^{1}$ \\ ${ }^{1}$ Pendidikan Biologi-Universitas Negeri Malang
}

\section{INFO ARTIKEL}

Riwayat Artikel:

Diterima: 22-02-2019

Disetujui: 16-08-2019

\section{kata kunci:}

antagonism handouts; cognitive learning outcomes; biology learning; handout antagonisme; hasil belajar kognitif; pembelajaran biologi

\author{
Alamat Korespondensi: \\ Arif Rahman \\ Pendidikan Biologi \\ Universitas Negeri Malang \\ Jalan Semarang 5 Malang \\ E-mail: arifblacks@gmail.com
}

\begin{abstract}
ABSTRAK
Abstract: Handout is a teaching materials that used to help students in understanding the subject matters that is have not written textbook. The development of handout Antagonism aims to improve the students cognitive learning outcomes. The handout development was based on the ADDIE development model. This handout was validated by the material validator and learning media validator, and the readability tests by students of X ATPH class. After that, the handout is used as teaching material in Biology learning process in X ATPH 1 class. The research results proved that the use of handouts Antagonism in the Biology learning process can improve students cognitive learning outcomes.

Abstrak: Handout merupakan bahan ajar untuk membantu siswa menguasai materi yang tidak terdapat pada buku teks. Tujuan pengembangan handout Antagonisme adalah untuk meningkatkan hasil belajar kognitif siswa. Pengembangan handout berdasarkan model pengembangan ADDIE. Handout divalidasi oleh validator materi dan validator media pembelajaran, serta dilakukan uji keterbacaan pada siswa kelas X ATPH. Selanjutnya, handout digunakan pada proses pembelajaran Biologi di kelas X ATPH 1. Hasil penelitian membuktikan bahwa penggunaan handout Antagonisme dalam proses pembelajaran Biologi dapat meningkatkan hasil belajar kognitif siswa.
\end{abstract}

Peningkatan Sumber Daya Manusia yang berkualitas ialah tujuan utama pendidikan di Indonesia. Tujuan tersebut dapat tercapai apabila semua aspek terkait dalam pendidikan dipersiapkan dengan baik sehingga menghasilkan sumber daya manusia yang berkualitas secara menyeluruh (Herlina, 2015). Secara umum, aspek-aspek tersebut meliputi sikap, pengetahuan dan keterampilan siswa (Walidin, 2016). Pada proses pencapaian tujuan pendidikan, terdapat beberapa faktor yang memengaruhinya. Salah satu faktor tersebut yaitu penggunaan bahan ajar (Sutrisno \& Siswanto, 2016). Penggunaan bahan ajar di SMKN 1 Malang khususnya dalam mata pelajaran Biologi pada jurusan Agribisnis masih terbatas. Belum ada materi dan penuntun praktikum yang berkaitan dengan pengendalian penyakit tanaman secara hayati menggunakan kapang/jamur sehingga menyebabkan kurangnya wawasan dan keterlibatan siswa dalam proses pembelajaran. Bahan ajar yang tidak dilengkapi dengan petunjuk praktikum menyebabkan para siswa kurang terlibat langsung dalam proses pembelajaran (Schmidt dkk, 2018). Hal ini berdampak negatif pada hasil belajar siswa yang dibuktikan dengan nilai pada topik Jamur, ketuntasan secara klasikal hanya sekitar 47\% siswa dari keseluruhan jumlah siswa kelas X ATPH 1 dan untuk kelas X ATPH 2 ketuntasan klasikalnya hanya sebesar 43\% dari keseluruhan jumlah siswa. Oleh karena itu, diperlukan adanya suatu bahan ajar yang menghasilkan suatu peningkatan pada hasil belajar siswa.

Berdasarkan hasil analisis kebutuhan bahan ajar pada 20 siswa responden menunjukkan bahwa seluruh siswa responden $(100 \%)$ merasa tertarik untuk mempelajari pengendalian penyakit tanaman secara hayati melalui pembelajaran baik teori maupun praktikum dengan topik “Antagonisme antara Kapang Antagonis dan Kapang Patogen” dan seluruh siswa responden (100\%) menyatakan perlu dibuatkan handout untuk membantu pembelajaran Biologi tentang topik tersebut. Selanjutnya, diharapkan penggunaan handout Antagonisme dapat memotivasi siswa dalam mengikuti proses pembelajaran karena materi handout tersebut disusun berdasarkan hasil penelitian eksperimen dari peristiwa yang terjadi di sekitar siswa sehingga dapat dipahami oleh para siswa karena bersifat faktual dan dapat menghasilkan peningkatan hasil belajar kognitif siswa. 


\section{METODE}

Penelitian pengembangan ini untuk mengembangkan bahan ajar berupa handout Antagonisme. Pengembangan handout ini berdasarkan pada ADDIE yang terdiri dari lima tahap, yaitu Analyze, Design, Develop, Implement dan Evaluate. Handout Antagonisme divalidasi oleh validator materi dan validator media pembelajaran, kemudian dilakukan uji keterbacaan pada 15 orang siswa kelas X ATPH. Data hasil validasi dan uji keterbacaan selanjutnya dianalisis dengan rumus berikut.

Keterangan:

$$
\mathrm{P}=\frac{\sum \mathrm{x}}{\sum \mathrm{xi}} \mathrm{X} 100 \%
$$

$\mathrm{P}=$ Hasil validasi

$\mathrm{x}=$ Total skor jawaban validator/responden

$\mathrm{xi}=$ Total skor maksimal

(Sa'dun Akbar, 2015)

Setelah diketahui hasil validasi, selanjutnya ditentukan keputusan uji sesuai kriteria pada tabel 1. Data hasil belajar kognitif yaitu berupa skor pretest dan postest dari kelas X ATPH 1 yang menggunakan handout dan kelas X ATPH 2 yang tidak menggunakan handout, serta dilakukan analisis uji T. Hal ini untuk membuktikan ada tidaknya perbedaan rerata hasil belajar kognitif kelas X ATPH 1 dengan X ATPH 2 berdasarkan skor pretest dan postest.

Tabel 1. Kriteria Penilaian Persentase Validitas Produk Pengembangan

\begin{tabular}{ccc}
\hline Persentase & Kriteria & Keputusan Uji \\
\hline $81 \% \leq \mathrm{P} \leq 100 \%$ & Sangat baik & Revisi pada sebagian kecil handout \\
$61 \% \leq \mathrm{P} \leq 80 \%$ & Baik & Revisi pada sebagian kecil handout \\
$41 \% \leq \mathrm{P} \leq 60 \%$ & Cukup Baik & Perlu revisi \\
$21 \% \leq \mathrm{P} \leq 40 \%$ & Kurang Baik & Perlu revisi \\
$0 \% \leq \mathrm{P} \leq 20 \%$ & Sangat kurang baik & Perlu banyak revisi \\
\hline
\end{tabular}

(Sumber: Akbar, 2013)

\section{HASIL}

Pengembangan handout Antagonisme telah divalidasi oleh validator materi dan validator media pembelajaran. Rangkuman data kuantitatif hasil validasi dari kedua validator tersebut pada tabel 3. Berdasarkan tabel 3 dapat dijelaskan bahwa hasil validasi handout Antagonisme oleh validator materi menunjukkan persentase sebesar 97,11\% dengan kriteria sangat baik, sedangkan validator media pembelajaran mendapatkan persentase sebesar 96,67\% dengan kriteria sangat baik sehingga menghasilkan keputusan uji handout yaitu revisi pada sebagian kecil handout. Data kualitatif yaitu berupa saran/masukan validator materi antara lain foto SEM tentang mekanisme antagonisme sebaiknya dilengkapi dengan petunjuk anak panah yang diatur agar lebih tepat menunjuk pada objek, sedangkan validator memberi saran agar warna media pembelajaran sebaiknya lebih dipertajam sehingga lebih kontras.

Pelaksanaan uji keterbacaan handout Antagonisme oleh 15 siswa kelas X ATPH 2. Data hasil uji keterbacaan siswa pada tabel 4. Berdasarkan tabel 4 tersebut dapat diketahui bahwa penilaian uji keterbacaan handout oleh siswa memberikan persentase sebesar 90,91\% dengan kriteria sangat baik sehingga keputusan uji yaitu perlu revisi pada sebagian kecil handout, dengan demikian handout Antagonisme ini layak digunakan pada pembelajaran Biologi yaitu pada materi Jamur. Hasil belajar kognitif yaitu berupa skor pretest dan postest pada kelas X ATPH 1 dan kelas X ATPH 2 dilakukan analisis dengan uji T untuk membuktikan ada tidaknya perbedaan rerata hasil belajar kognitif berdasarkan skor pretest dan postest pada tabel 5 .

Tabel 3. Hasil Validasi Validator Materi dan Validator Media Pembelajaran

\begin{tabular}{ccccc}
\hline No. & Validator & Persentase & Kriteria & Keputusan Uji \\
\hline 1. & Validator materi & $97,11 \%$ & Sangat baik & \multirow{2}{*}{ Revisi pada sebagian kecil handout } \\
2. & Validator media pembelajaran & $96,67 \%$ & Sangat baik & \\
\hline
\end{tabular}

Tabel 4. Hasil Uji Keterbacaan Siswa terhadap Handout Antagonisme

\begin{tabular}{cccc}
\hline Responden & Persentase & Kriteria & Keputusan Uji \\
\hline Siswa & $90,91 \%$ & Sangat baik & Revisi pada sebagian kecil handout \\
\hline
\end{tabular}


Tabel 5. Hasil Analisis Uji T Tidak Berpasangan

\begin{tabular}{|c|c|c|c|c|c|c|c|c|c|c|}
\hline & & \multicolumn{2}{|c|}{$\begin{array}{c}\text { Levene's Test for } \\
\text { Equality of } \\
\text { Variances } \\
\end{array}$} & \multicolumn{7}{|c|}{ t-test for Equality of Means } \\
\hline & & \multirow[t]{2}{*}{$\mathrm{F}$} & \multirow[t]{2}{*}{ Sig. } & \multirow[t]{2}{*}{$\mathbf{t}$} & \multirow[t]{2}{*}{ df } & \multirow[t]{2}{*}{$\begin{array}{l}\text { Sig. (2- } \\
\text { tailed) }\end{array}$} & \multirow[t]{2}{*}{$\begin{array}{c}\text { Mean } \\
\text { Difference }\end{array}$} & \multirow{2}{*}{$\begin{array}{l}\text { Std. } \\
\text { Error } \\
\text { Differ } \\
\text { ence }\end{array}$} & \multicolumn{2}{|c|}{$\begin{array}{l}\text { 95\% Confidence } \\
\text { Interval of the } \\
\text { Difference }\end{array}$} \\
\hline & & & & & & & & & Lower & Upper \\
\hline \multirow{2}{*}{$\begin{array}{c}\text { Hasil } \\
\text { Belajar } \\
\text { Kognitif }\end{array}$} & $\begin{array}{l}\text { Equal variances } \\
\text { assumed }\end{array}$ & 12.661 & .001 & 3.261 & 60 & .002 & 9.032 & $\begin{array}{c}2.77 \\
0\end{array}$ & 3.492 & 14.572 \\
\hline & $\begin{array}{l}\text { Equal variances } \\
\text { not assumed }\end{array}$ & & & 3.261 & 46.519 & .002 & 9.032 & $\begin{array}{c}2.77 \\
0\end{array}$ & 3.459 & 14.606 \\
\hline
\end{tabular}

Berdasarkan analisis menggunakan uji $\mathrm{T}$ tersebut, diketahui Sig. (2-tailed) sebesar 0,002 $<0,05$, maka ada perbedaan rerata hasil belajar kognitif kelas X ATPH 1 yang menggunakan handout Antagonisme dengan X ATPH 2 yang tanpa menggunakan handout Antagonisme. Selanjutnya, untuk mengetahui rerata hasil belajar kognitif yang tertinggi dari kelas $\mathrm{X}$ ATPH 1 dan X ATPH 2 terdapat pada tabel 6.

Tabel 6. Rerata Hasil Belajar Kognitif

\begin{tabular}{lccccc}
\hline & Kelas & N & Mean & Std. Deviation & Std. Error Mean \\
\hline \multirow{2}{*}{ Hasil Belajar Kognitif } & X ATPH 1 & 31 & 84.68 & 7.409 & 1.331 \\
& X ATPH 2 & 31 & 75.65 & 13.524 & 2.429 \\
\hline
\end{tabular}

Berdasarkan tabel 6 dapat diketahui bahwa rerata hasil belajar kognitif kelas X ATPH 1 sebesar 84,68, sedangkan kelas X ATPH 2 sebesar 75,65. Hal ini dapat disimpulkan bahwa rerata hasil belajar kognitif kelas X ATPH 1 yang menggunakan handout lebih tinggi dibandingkan dengan rerata hasil belajar kognitif siswa kelas X ATPH 2 yang tidak menggunakan handout.

\section{PEMBAHASAN}

Suatu pembelajaran dapat dikatakan berhasil jika pelaksanaan pembelajaran tersebut memberikan dampak positif terhadap siswa. Dampak tersebut adalah peningkatan hasil belajar siswa, yaitu sikap, pengetahuan, dan keterampilan. Peningkatan hasil belajar siswa merupakan cerminan dari penguasaan materi oleh siswa. Untuk menciptakan kondisi tersebut adalah dengan penggunaan bahan ajar yang dapat membantu meningkatkan penguasaan materi oleh siswa.

Handout merupakan salah satu contoh bahan ajar yang disusun berdasarkan materi-materi yang relevan terhadap kompetensi yang dipelajari, namun materi tersebut tidak terdapat pada buku teks (Munyoro, 2014). Pengembangan handout yang disusun berdasarkan pada kebutuhan siswa merupakan cara yang terbaik untuk meningkatkan pemahaman siswa (Novitaningrum, Parmin, \& Pamelasari, 2014; Purwanto, Kelik, \& Rahmawati, 2017; Wulandari \& Suarsini, 2016). Penerapan penggunaan handout Antagonisme pada proses pembelajaran Biologi menunjukkan terjadi peningkatan hasil belajar kognitif. Hasil analisis uji T dapat diketahui bahwa terjadi perbedaan rerata peningkatan hasil belajar kognitif siswa kelas X ATPH 1 yang menggunakan handout dengan siswa kelas X ATPH 2 yang tidak menggunakan handout. Kelas X ATPH 1 yang menggunakan handout menunjukkan rerata hasil belajar tertinggi jika dibandingkan dengan kelas X ATPH 2 yang tidak menggunakan handout.

Proses pembelajaran menggunakan handout lebih efektif meningkatkan hasil belajar kognitif siswa dibandingkan dengan tanpa menggunakan handout Antagonisme. Hal ini dikarenakan handout Antagonisme disusun dari hasil penelitian eksperimen berdasarkan fenomena yang ada di lingkungan sekitar siswa sehingga menjadikan handout bersifat faktual dan kontekstual. Handout yang bersifat kontekstual akan meningkatkan pemahaman siswa karena siswa dapat menghubungkan materi dengan fenomena yang ada dalam kehidupan nyata (Wulandari dkk, 2016). Penggunaan handout merupakan salah satu cara menjadikan proses pembelajaran lebih efektif sehingga menyebabkan peningkatan penguasaan materi oleh siswa. Penggunaan handout dapat menciptakan lingkungan pembelajaran yang lebih efektif dan berdampak baik terhadap hasil belajar siswa (Avval, Jarahi, Ghazvini, \& Youssefi, 2013; Motagi \& Dharwadkar, 2018).

\section{SIMPULAN}

Handout Antagonisme ini terbukti efektif untuk meningkatkan hasil belajar kognitif, hal ini berdasarkan pada analisis uji $\mathrm{T}$ yang menyatakan bahwa terjadi perbedaan rerata peningkatan hasil belajar kognitif kelas X ATPH 1 yang menggunakan handout dengan kelas X ATPH 2 tanpa menggunakan handout. Dengan demikian, dapat disimpulkan bahwa rerata hasil belajar kognitif kelas yang menggunakan handout Antagonisme lebih tinggi jika dibandingkan hasil belajar kelas yang tidak menggunakan handout Antagonisme. 


\section{DAFTAR RUJUKAN}

Akbar, S. (2017). Instrumen Perangkat Pembelajaran. Bandung: Remaja Rosdakarya.

Avval, F. Z., Jarahi, L., Ghazvini, K., \& Youssefi, M. (2013). Distribution of Handouts in Undergraduate Class to Create More Effective Educational Environment. International Journal of Education and Research, 1(12), 1-6.

Herlina. (2015). Pendidikan dan Pelatihan (Diklat) Peningkatan Kualitas Sumber Daya Manusia. Jurnal Kependidikan, 14(1), 37-44.

Motagi, M. V., \& Dharwadkar, K. (2018). Evaluation of the Effectiveness of Providing Powerpoint Slide Handouts Before the Class. International Journal of Medical Science and Public Health, 7(9), 736-740. https://doi.org/10.5455/ijmsph.2018.0205413062018

Munyoro, G. (2014). An Evaluation of the Effectiveness of Handouts in Enhancing Teaching and Learning in Higher Education. Africa Development and Resources Research Institute (Adrri) Journal, 5(5), 1-19.

Novitaningrum, M., Parmin., \& Pamelasari, S. D. (2014). Pengembangan Handout IPA Terpadu Berbasis Inkuiri pada Tema Mata untuk Kelas IX Siswa MTs Al-Islam Sumurejo. Unnes Science Education Journal, 3(2), 542-546.

Purwanto, Kelik \& Rahmawati, A. (2017). Pengembangan Handout untuk Siswa Kelas V SDN 14 Koto Baru pada Materi Bermain Drama. Jurnal Tarbiyah, 24(1), 137-156.

Schmidt, J. A., Rosenberg, J. M., \& Beymer, P. N. (2018). Research Article A Person-in-Context Approach to Student Engagement in Science : Examining Learning Activities and Choice. 55(1), 19-43. https://doi.org/10.1002/tea.21409

Sutrisno, V. L. P., \& Siswanto, B. T. (2016). Faktor-faktor yang Memengaruhi Hasil Belajar Siswa pada Pembelajaran Praktik Kelistrikan Otomotif SMK di Kota Yogyakarta. Jurnal Pendidikan Vokasi, 6(1), 111-120. https://doi.org/10.21831/jpv.v6i1.8118

Walidin, W. (2016). Arah Pengembangan Sumberdaya Manusia Dalam Dimensi Pendidikan Islam. Jurnal Edukasi, 2(2), 147163.

Wulandari, S., Suarsini, E., \& Ibrohim. (2016). Pemanfaatan Sumber Belajar Handout Meningkatkan Pemahaman Konsep Mahasiswa S1 Universitas Negeri Malang. Jurnal Pendidikan: Teori, Penelitian, dan Pengembangan, 1(5), 881-884. 